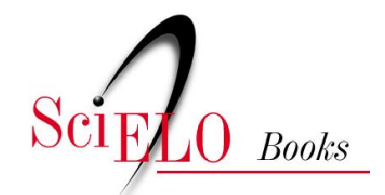

\title{
Vieira e a alegoria dos teólogos e do Renascimento
}

\author{
Marcelle Ventura Carvalho
}

\section{SciELO Books / SciELO Livros / SciELO Libros}

CARVALHO, MV. Vieira e a alegoria dos teólogos e do Renascimento. In: MEDEIROS, A., org. Travessias pela literatura portuguesa: estudos críticos de Saramago a Vieira [online]. Campina Grande: EDUEPB, 2013, pp. 207-240. ISBN 9788578792794. Available from SciELO Books $<\underline{\text { http://books.scielo.org }>}$

\section{@)(1)(9)}

All the contents of this work, except where otherwise noted, is licensed under a Creative Commons Attribution-Non Commercial-ShareAlike 3.0 Unported.

Todo o conteúdo deste trabalho, exceto quando houver ressalva, é publicado sob a licença Creative Commons Atribuição Uso Não Comercial - Partilha nos Mesmos Termos 3.0 Não adaptada.

Todo el contenido de esta obra, excepto donde se indique lo contrario, está bajo licencia de la licencia Creative Commons Reconocimento-NoComercial-CompartirIgual 3.0 Unported. 


\title{
Vieira e a alegoria dos teólogos e do Renascimento
}

\author{
Marcelle Ventura Carvalho
}

Percorrendo a estrada da literatura lusitana, deparei-me com os escritos de padre Antônio Vieira. Foi surpreendente poder "compreender" um discurso "barroco", cuja clareza o tornou legível para quem estava pouco acostumada com o estilo vieiriano. A impressão causada pela simplicidade, pela elegância do texto e pela agudeza das imagens despertou-me o desejo de explorar a dialética desse homem, alfaiate das palavras, que costurava suas ideias usando como tecido, o mundo; como linha, a história; como agulha, a palavra.

Padre António Vieira (1608-1697) foi um gigante; embora, em alguns momentos, tenha sido um gigante vencido. Dividiu-se entre a Europa e as Colônias Portuguesas, desfrutando, em certos períodos, de consideráveis privilégios políticos. Foi missionário, pregador, diplomata, político e escritor. Nasceu em Lisboa e, aos sete anos, mudou-se com a família para a Bahia, no Brasil, onde o pai exercia 
a função de secretário do Governo. Estudou no colégio jesuíta da Bahia e ingressou na Companhia de Jesus, recebendo ordens em 1635 e iniciando nessa altura o seu trabalho como pregador. Em 1641, partiu para Lisboa com o governador para apresentar ao rei D. João IV a adesão à causa da Restauração. O rei encarregou-o de várias missões diplomáticas na Holanda e em Roma. Não sendo bem sucedido nestes encargos, regressou novamente ao Brasil e dedicou-se à catequização dos índios. Após a morte de D. João IV, a Inquisição acusa-o de professar opiniões heréticas (1662-1667), mas é absolvido com a subida ao trono de D. Pedro II. Depois de novo e intenso período de trabalho como diplomata em Roma e como pregador, regressou definitivamente à Bahia, onde morreu com quase 90 anos de idade. Além dos Sermões (13 tomos publicados entre 1679 e 1699), escreveu Esperanças de Portugal, Clavis Prophetarum e História do Futuro, obras de conteúdo profético (LISBOA, 1970).

Diante de uma existência tão intensa, Pécora (1995), em Tópicas políticas dos escritos de Antônio Vieira e outros textos, divide a vida e a obra de Vieira em quatro períodos: o primeiro inicia-se em 1623, com a formação de Vieira nos colégios da Companhia de Jesus e finaliza em 1641, data da sua primeira ida a Portugal; o segundo compreende a época em que o orador conheceu o rei D. João IV, seu amigo e valido, em 1641, prolongando-se até 1651, quando se prepara para voltar à Colônia com o objetivo de realizar a "missão do Maranhão"; o terceiro começa em 1652, quando retorna ao Maranhão, estendendo-se até 1661, quando foi expulso da Colônia; o quarto, e último período, inicia-se 
com a morte de D. João IV, o afastamento de D. Luísa de Gusmão e a coroação do novo rei D. Afonso VI em 1662, finalizando com a morte do pregador em 1697.

Costurando os momentos da vida multifacetada de Vieira, vê-se que algo a uniformiza, a saber: a agudeza oratória. No entanto, essa mesma agudeza é apreciada de maneira distinta entre vários pesquisadores do orador barroco.

Considerando-se o estilo de Vieira, José Aderaldo Castello (1999, p. 83-84) afirma que “[...] o Pe. Antônio Vieira atingirá o último dos nossos grandes oradores, Rui Barbosa, de reconhecido nível literário, ostensivamente preocupado com a pureza da língua”. Discordando de Aderaldo Castello - e de outros autores, que supervalorizaram o pregador como exemplo de estilista da língua portuguesa -, Pécora, em Teatro do Sacramento, critica essa imagem estereotipada do jesuíta ressaltando que:

Mesmo essa idéia de grande orador, indiscutida e indiscutível, desdobra-se em outras muito diversas, e, a meu ver anacrônicas e inadequadas objetivamente. É o caso daquelas que o fazem uma espécie de estilista licenciado ou bacharel de letras, próximo, portanto, de autores como Coelho Neto e Rui Barbosa, ou, se se preferir, de um parnasiano em botão. Castilho, nos anos românticos, já dera um acentuado tom de guardião da puridade do idioma a Vieira, além de estendê-lo a Manuel Bernardes. E, entretanto, conquanto essa imagem de Antônio Vieira tenha tido grande alcance, mormente 
no Brasil, em que as referências históricas têm sempre muito menos peso, deve ser completamente claro para quem o lê com um mínimo de isenção e rigor que não há nele qualquer cultivo da língua por ela mesma, como nunca houve, o que já foi dito mais atrás, qualquer idéia sua dos sermões como literatura autônoma e projeto estético - a despeito do soberbo valor estético que se possa reconhecer neles. (PÉCORA, 1994, p. 45).

Se não há em Vieira, como afirma Pécora (1994), a preocupação estética - e já aí o termo "estética” é anacrônico para o orador, visto surgir apenas no século XIX - qual então a função das alegorias nas prédicas vieirianas? Como se sabe, as figuras e tropos de linguagem, desde a Retórica Antiga, assumiram o papel de embelezadores do discurso. Que sentido adquirem em um discurso que não visa, necessariamente, ao belo?

A partir desses questionamentos, lancei-me ao intento de analisar como e com qual propósito o orador construía as suas alegorias.

Como todo pesquisador, sempre que nos deparamos com nosso objeto de estudo sentimos a necessidade de recorrer a definições, pois percebemos que elas nos indicam os limites precisos das fronteiras semânticas dos vocábulos. Assim procedemos com o termo "Alegoria", e, num primeiro momento, percorri as linhas escritas por Aristóteles (1998) em Arte retórica e arte poética. Embora o filósofo não indique o conceito específico para o termo, ele agrupa todas as figuras que se particularizam pelo deslocamento 
de sentido e as define como "metáfora", que seria "[...] a transposição do nome de uma coisa para outra, transposição do gênero para a espécie, ou da espécie para o gênero, ou de uma espécie para outra, por via da analogia" (1998, p. 275). Cícero, orador latino, compartilha do conceito aristotélico e, ao mesmo tempo, amplia-o ao definir a Alegoria como metáfora continuada

Llamo metáforas, como ya he dicho muchas veces, a aquellas palabras que cambian su significado gracias a su semejanza con otra, ya por razones de encanto, ya por razones de falta de la palabra con significado propio. Cuando siguen muchas metáforas continuadas, se produce un discurso diferente; por ello los griegos llaman a esta figura "alegoría": el término utilizado es correcto, pero tiene razón Aristóteles que, genéricamente, llama metáforas a todas estas figuras. (CÍCERO, 1997a, p. 74- 75).

Essa alteração ou mudança de significado baseada na analogia ou semelhança é, para Quintiliano, o que determina o tropo, uma vez que ele o define nestes termos: "A Alegoria, que nós interpretamos Inversão do sentido, é a que mostra uma coisa nas palavras, e outra no sentido, e às vezes também o contrário" (QUINTILIANO, 1944, p. 121); ou seja, diz-se $b$ para significar $a$, disso pode-se inferir que a compreensão do termo alegórico implica na retirada do véu figurativo por parte de um dos constituintes do discurso (emissor - receptor). 
No Sermão de Santo Antônio aos Peixes, pregado na cidade de São Luís do Maranhão, no ano de 1654, Vieira afirma metaforicamente que os pregadores são o sal da terra, logo, a sua função é a de conservar a fé cristã; no entanto, a corrupção do mundo é tal que atinge não apenas os ouvintes, mas os próprios pregadores que se distanciam do éthos cristão. No decorrer da homilia, os padres e os ouvintes são representados pelos habitantes do mundo marítimo, a partir das semelhanças que se verificam entre eles. Observe como Vieira desenvolve a seguinte imagem:

Rodeia a Nau o Tubarão nas calmarias da Linha com seus Pegadores às costas, tão cerzidos com a pele, que mais parecem remendos, ou manchas naturais, que os hóspedes ou companheiros. Lançam-lhe um anzol de cadeia com a ração de quatro soldados, arremessa-se furiosamente à presa, engole tudo de um bocado, e fica preso. Corre meia campanha a alá-lo acima, bate fortemente o convés com os últimos arrancos; enfim, morre o Tubarão, e morrem com ele os Pegadores. (VIEIRA, 2000, p. 333-334).

Todo esse sermão é alegórico, ou seja, Vieira diz $b$, para significar $a$. O orador critica a corrupção da humanidade, alegoricamente nomeada de "peixe". A alegoria é construída a partir da analogia de atribuição estabelecida por Vieira, que transpõe o comportamento dos peixes para os homens. O que proporciona a alegoria é a agudeza do orador que aproxima conceitos distintos "peixe" e "homem", criando a analogia de atribuição a partir de "supostas" semelhanças, 
visto que, no mar, alguns peixes grudam no corpo de peixes maiores para alimentar-se dos restos da refeição de seus hóspedes.

No fragmento apresentado, “Tubarão" é a metáfora usada para o Vice-Rei ou os Governadores das Colônias; "Pegadores" é a metáfora referente aos bajuladores e parasitas que acompanham os Governadores, dependendo destes para sobreviverem. Usado do artifício alegórico, Vieira transmite verdades morais, ao mesmo tempo em que denuncia os vícios da humanidade e a situação política da Colônia.

No Sermão da Sexagésima, exemplo de meta-sermão, o orador inicia a prédica com o fragmento bíblico: Semen est verbum Dei, a semente é a palavra de Deus; se a palavra de Deus é a semente, deduz-se que o discurso que dela brota é uma árvore. Assim, Vieira descreve alegoricamente o sermão a partir da imagem da planta, pois a árvore tem, na sua base, a raiz; a base do sermão é o Evangelho, o discurso deve germinar dessa raiz. O tronco é o assunto, a árvore possui um só tronco, assim também o sermão deve ter um só assunto. Os ramos são os mais diversos discursos que nascem do mesmo tronco ou matéria, assim como os troncos das árvores são diferentes uns dos outros, assim também os discursos serão distintos devido ao estilo de cada orador, mas todos são provenientes do mesmo tronco e raiz. As folhas embelezam as árvores; as palavras adornam no discurso com metáforas e outras figuras de estilo, pensamento ou linguagem. As varas, presentes nas árvores, são os chicotes verbais que repreendem os vícios. As flores são as sentenças que purificam a alma. O fruto é o que se colhe da árvore e o que vai ser colhido do sermão: a persuasão. 


\section{4}

O sermão deve ser uma árvore completa com raiz, tronco, galhos, varas, folhas, flores e frutos, pois

[...] se tudo são troncos, não é sermão, é madeira. Se tudo são ramos, não é sermão, são maravalhas. Se tudo são folhas, não é sermão, são versas. Se tudo são varas, não é sermão, é feixe. Se tudo são flores não é sermão é ramalhete. Serem tudo fruto não pode ser; porque não há fruto sem árvore.(VIEIRA, 2000, p. 42).

No mesmo sermão, outra imagem alegórica é empregada na argumentação do orador, a saber: as palavras devem ser como as estrelas, distintas e claras. Assim como as estrelas compõem a "tapeçaria" do céu, assim as palavras compõem o sermão. Para que esta "tapeçaria" divina seja agradável aos olhos, as estrelas devem estar em harmonia, ordem e curso definidos, assim também devem estar as palavras no discurso (VIEIRA, 2000, p. 40).

Assim há de ser o estilo da pregação, muito distinto e muito claro. E nem por isso temais que pareça o estilo baixo; as estrelas são muito distintas e muito claras e altíssimas. $\mathrm{O}$ estilo pode muito claro e muito alto; tão claro que o entendam os que não sabem, e tão alto que tenham muito que entender nele os que sabem. $\mathrm{O}$ rústico acha documento nas estrelas para sua lavoura, e o mareante para sua navegação, e o matemático para suas observações e para seu juízo. De maneira que o rústico e o mareante, que não sabem ler, entendem as estrelas, e o matemático que tem lido quantos escreveram não alcançam a entender quanto nelas há. (VIEIRA, 2000, p. 40). 
Vieira, nessa passagem, recupera o pensamento de Cícero a respeito do estilo tênue, pois o orador romano afirmou que: "Es um estilo sencillo, bajo, cuyo modelo es el lenguaje normal, pero más cercano em realidad a la elocuencia de lo que normalmente se cree".(CÍCERO, 1997a. p. 67).

De modo semelhante ao Sermão de Santo Antônio aos Peixes, a função primeira da alegoria é argumentativa. No primeiro sermão, ela é argumento político; no segundo, retórico-teológico.

Note-se que a alegoria foi criada pelo orador, ela é, portanto, fruto de sua subjetividade. Esse tipo de construção alegórica Hansen (1987) denomina "Alegoria dos poetas" e se tornou comumente empregada na literatura, visto que ela demonstra a criatividade de quem a elabora e proporciona beleza e elegância ao discurso. Mas, no caso específico de Vieira, é-lhe acrescentada outra função: a de prova retórica, função esta que se torna mais importante do que um simples ornamento, como normalmente é utilizada.

No entanto, a tipologia do tropo é tripartida, devendo-se, portanto, acrescentar as Alegorias dos Teólogos e as Alegorias do Renascimento, ambas produzidas e empregadas com fins específicos. 


\section{Alegoria dos Teólogos}

Se, como mostrado anteriormente, Alegoria dos Poetas é a construção do autor, a Alegoria dos Teólogos é a construção de Deus. Se na Alegoria dos Poetas metaforizam-se termos, na Alegoria dos Teólogos metaforizam-se fatos, daí ser chamada também de Alegoria Factual. Os poetas criam suas alegorias, os teólogos interpretam a alegoria "escrita" por Deus. Para os teólogos, Deus escreveu dois livros: o Universo visível e as Sagradas Escrituras, deixando nessas obras as suas marcas ocultas (HANSEN, 1987, p. 45).

O teólogo, exegeta ou hermeneuta, procura decifrar as marcas divinas no tempo, na história, na natureza, no cosmos, na Bíblia; visto que se Deus é a causa de tudo o que existe, então tudo conserva os vestígios do seu Criador, como efeitos da Causa primeira. O homem deve olhar para a natureza procurando sempre um recado oculto do Idealizador do mundo. Por exemplo, no Sermão da Terceira Dominga da Quaresma, pregado na capela real, no ano de 1655 , Vieira pronuncia o seguinte:

Quando Deus deu forma ao governo do mundo, pôs no Céu aqueles dois grandes Planetas, o Sol e a Lua, e deu a cada um deles uma presidência: ao Sol, a presidência do dia: Luminare maius, ut praeesset diet; e à Lua a presidência da noite: Luminare minus, ut praeesset nocti. E por que fez Deus esta repartição? Porventura por que se não queixasse a Lua e as Estrelas? Não, porque com o Sol ninguém tinha competência, nem podia ter justa queixa. Pois, se o Sol tão conhecidamente 
excedia a tudo quanto havia no Céu; por que não proveu Deus nele ambas as presidências? Por que lhe não deu ambos os ofícios? Por que ninguém pode fazer bem dois ofícios, ainda que seja o mesmo Sol. O mesmo Sol quando alumia um hemisfério, deixa o outro às escuras. E que haja de haver homem com dez hemisférios! E que cuide, ou se cuide, que em todos pode alumiar! Não vos admiro a capacidade do talento, a da consciência sim. (VIEIRA, 2000, p. 152).

O jesuíta, lançando mão da alegoria, critica os ministros que acumulam cargos sem poder desempenhá-los adequadamente. $\mathrm{O}$ modo como Deus organizou o mundo é uma alegoria de como o homem deve organizar-se politicamente. A noite, o dia, o sol e a lua passam de astros a índices, signos divinos que falam ao homem. Esses signos divinos são encontrados no Universo e nas Sagradas Escrituras. Partindo desse pressuposto, os padres e os teólogos da Idade Média como São Boaventura, Santo Agostinho, Beda ${ }^{1}$ e Santo Tomás de Aquino leram o Velho Testamento como alegoria divina dos acontecimentos futuros, isto é, dos fatos que ocorreriam no Novo Testamento. Logo o Velho Testamento é a prefiguração dos fatos que ocorrem no Novo Testamento. Esse dois textos podem ser lidos no seu sentido literal, ou no seu sentido figurado. Por exemplo, quando Moisés, no Êxodo, sai do Egito

1 Beda, o venerável. Monge e historiador inglês (673-735). Dotado de grande saber enciclopédico, escreveu "História eclesiástica da nação inglesa". Segundo Hansen (1987, p. 53), foi o primeiro a assimilar a interpretação tipológica da Bíblia a categorias retóricas da alegoria antiga. 
libertando os judeus é um fato histórico, que pode ser lido literalmente. Mas, pode também ser interpretado como a prefiguração da vida de Cristo. Porque Moisés é o salvador dos judeus, assim como Cristo é o salvador da humanidade. Outro exemplo é o de Abrão, que teve dois filhos um de escrava, outro de mulher livre. Trata-se de fato histórico, mas que pode também ser lido figuradamente. Os dois filhos de Abrão prefiguram a existência dos dois testamentos; os filhos da escrava prefiguram os judeus escravizados no Egito, com os quais Deus estabeleceu a Velha Aliança; os filhos da mulher livre prefiguram os cristãos com quem Deus estabelece a Nova Aliança.

Note-se que um fato histórico prefigura outro fato também histórico, mas situados em épocas distintas. Como afirma Hansen, trata-se de uma "operação redundante" em que "ler é reler o mesmo em suas variações minuciosas". Eis um exemplo da utilização feita por Vieira da alegoria dos teólogos, no Sermão da Degolação de São João Batista, proferido em Odivelas, no ano de 1652:

Uma das mais notáveis coisas da Escritura é a vida da mulher de Jô. Tinha Deus concedido ao diabo, que naquela grande casa pudesse fazer ou desfazer contra ele, tudo o que o seu ódio, sua astúcia e maldade julgassem conveniente para o vencer, exceto somente a vida do mesmo Jô [...] Começou pois o diabo matando e degolando tudo quanto vivia na mesma família [...] Mas o que é mais digno de nota em tão comum e universal estrago, é, que entre tantas mortes ficasse contudo viva a senhora da casa, a mãe dos filhos, e a mulher do pai? [...] S. Basílio, S. 
Crisóstomo, os dois Gregórios, e todos os Santos Padres, comumente dizem [...] que assim como o demônio se não atreveu a acometer a Adão por si mesmo, senão pela primeira Eva, assim agora entendeu que para derrubar aquela torre [...] não poderia por si mesmo; e por essa razão deixara viva a Jô a sua segunda Eva, para que por meio dela perseguido o quebrantasse, ou persuadido o rendesse, que são dois modos, um duro, outro brando, com que o demônio (diz o Grande Gregório) forte e suavemente costuma conseguir o que intenta. (VIEIRA, 2000, p. 521-522).

Vieira, baseando-se nos Padres da Igreja, apresenta Eva como prefiguração da mulher de Jó, isto é, como a prefiguração de todas as mulheres que, no Livro Sagrado, incitam seus maridos a pecar. Assim, um fato histórico, o pecado de Eva, prefigura outro fato histórico, o pecado da mulher de Jó. Eva peca contra Deus, do mesmo modo que a mulher de Jó. Esse processo resulta na analogia de proporção. Os comportamentos das mulheres são proporcionalmente análogos. Note-se que, na analogia de proporção, algo está para algo, por outras palavras, Eva está para mulher de Jó, assim como Moisés está para Cristo, assim como os dois filhos de Abrão estão para os dois testamentos.

Graficamente a demonstração dos tipos de analogia seria da seguinte forma: a analogia de atribuição (presente na alegoria dos poetas) compreende uma linha vertical finita que acabaria junto com o próprio texto, existindo no momento de sua expressão, ao passo que a analogia de proporção seria uma linha horizontal desenvolvida no tempo indefinidamente, ou até o fim dos tempos, até a realização 
do Apocalipse 2 , pois os fatos sempre se prestam a novas prefigurações. Já foi dito que Moisés prefigura Cristo; mas ele pode prefigurar também os jesuítas, que no Brasil lutam para libertar os índios de cativeiros injustos, pois "os jesuítas por sua vez acreditavam estar repetindo papéis anteriormente desempenhados seja por Cristo, seja pelos apóstolos ou pelos mártires." (VILAR, 2006, p. 5).

Cabe à agudeza do hermeneuta descobrir a proporção analógica dos fatos. A alegoria, presente na analogia de proporção, compreende o segundo nível de possibilidade de leitura das Escrituras. Segundo Rábano Mauro (apud HANSEN, 1987, p. 49), podem-se ler as passagens bíblicas de quatro modos, a saber: Histórico, Alegórico (ou Cristológico), Tropológico (ou Moral) e Anagógico (ou Escatológico). Logo, a saída de Moisés do Egito libertando os judeus teria quatro significações. Historicamente é fato que aconteceu. Alegoricamente prefiguraria Cristo, como já visto. Tropologicamente, ou em sentido moral, a libertação dos escravos é a alma humana que é resgatada por Deus. Anagogicamente, ou em sentido escatológico, é a ida da alma liberta, para o além, saindo do cativeiro do corpo. Atente-se que o nível alegórico, segundo Rábano Mauro, refere-se unicamente a Cristo, ou seja, o figurado é Cristo, sua vida, morte e ressurreição; os outros sentidos velados pertencem a categorias diferentes, tropológicos ou anagógicos.

2 Apocalipse. Qualquer dos antigos escritos judaicos ou cristãos (especialmente o último livro canônico do Novo Testamento, atribuído a São João) que contém revelações, em particular sobre o fim do mundo e apresentadas, quase sempre, sob a forma de visões. 
O Sermão dos Bons Anos, pregado em Lisboa, na Capela Real, no ano de 1961, demonstra o emprego alegórico ou cristológico das passagens bíblicas. Ele se refere ao Salmo 40 em que:

Descreve Davi o meio extraordinário por onde os procedimentos injustos de um mau homem dariam princípio à redenção de todos, como seria traído o Redentor, como o pretenderiam derrubar por engano do seu estado; e intimando o Senhor o caso aos Discípulos disse estas particulares palavras: Dico vobis antequam fiat, ut cum factum fuerit credatis, quia ego sum. Eu sou este de quem aqui fala Davi. (VIEIRA, 2000, p. 367).

Vieira se apropria do texto de Jó (13:19) para demonstrar que Cristo fora prefigurado nessas palavras: "Desde agora vo-lo digo, antes que suceda, para que, quando suceder, creiais que sou eu."

Embora se observe, como na passagem acima, o emprego de passagens cristológicas nos sermões de Vieira, optou-se, nas análises das alegorias vieirianas, não seguir essa divisão, por entender os sentidos tropológico e anagógico e cristológico como alegóricos, visto que dizem algo se referindo ao que está velado, seja Cristo, seja a alma humana, seja o fim dos tempos. Segue-se, nas análises aqui desenvolvidas, a distinção estabelecida por Beda. Embora Santo Tomás de Aquino, também, tenha estudado a alegoria, a sua visão distancia-se das de Beda e de Santo Agostinho, por valorizar excessivamente a alegoria dos teólogos, desprezando, e mesmo anulando, a alegoria dos 
poetas. Para Tomás de Aquino só existe alegoria na Bíblia, o homem elabora apenas sentidos literais próprios ou figurados. Veja-se, a título de esclarecimento, o diagrama das distinções elaboradas por Santo Agostinho, Beda e Santo Tomás de Aquino a respeito da alegoria. (HANSEN, 1987, p. 51-58).

\begin{tabular}{|c|c|c|c|}
\hline \multicolumn{2}{|c|}{ Santo Agostinho } & \multicolumn{2}{|c|}{ Beda } \\
\hline $\begin{array}{c}\text { Signos } \\
\text { naturais }\end{array}$ & $\begin{array}{c}\text { Signos } \\
\text { instituídos }\end{array}$ & \multirow{3}{*}{$\begin{array}{l}\text { Allegoria in } \\
\text { verbis } \\
\downarrow\end{array}$} & \multirow{5}{*}{$\begin{array}{c}\text { Allegoria in } \\
\text { factis } \\
\qquad \\
\text { Ornamento }\end{array}$} \\
\hline$\downarrow$ & & & \\
\hline Profano & Divino & & \\
\hline $\begin{array}{l}\text { Signos } \\
\text { próprios } \\
\downarrow\end{array}$ & $\begin{array}{c}\text { Signos } \\
\text { translatos } \\
\downarrow\end{array}$ & Tropo & \\
\hline Ornamento & Figura & & \\
\hline \multicolumn{4}{|c|}{ Santo Tomás de Aquino } \\
\hline Sentido lite & histórico & \multirow{3}{*}{\multicolumn{2}{|c|}{$\begin{array}{l}\text { Sentido literal próprio } \\
\downarrow \\
\text { Sentido literal figurado }\end{array}$}} \\
\hline & & & \\
\hline Sentido & ritual & & \\
\hline
\end{tabular}

Os signos naturais e instituídos são, segundo Santo Agostinho, semelhantes aos que hoje são designados por "índice". São naturais os signos, ou índices, que não são criados pelo homem, verbi gratia: a neve é signo natural de inverno, a fumaça é signo natural de fogo, o sol é signo 
natural do dia etc. Os signos instituídos são os criados pelo homem, vale dizer: as bandeiras e os emblemas; os signos divinos de instituição são índices que não são criados por homens comuns, mas pelos que escreveram as Escrituras, como Davi, no salmo 22.1, institui para Deus o signo de "pastor" que passa a ser índice do Senhor. O grupo seguinte de signos, de acordo com Santo Agostinho, compreende os signos próprios e os signos translatos. Por próprio entende-se o nome que designa diretamente as coisas. Os translatos são os signos figurados, dos quais faz parte a alegoria, comportando-se de dois modos: como ornamento de palavras, alegoria verbal, seguindo os passos da retórica antiga, ou como alegoria de fatos bíblicos, em que um fato figura outro fato. A alegoria verbal é o tropo que Hansen chama de alegoria "dos poetas". A alegoria de fatos é a que Hansen nomeia de "alegoria dos teólogos".

Beda retoma Santo Agostinho e a retórica antiga, mantendo a fragmentação dos signos em próprios e translatos ou figurados. A sua contribuição é a sistematização e a explicação do tipo de alegoria. Beda divide a alegoria em duas: allegoria in verbis (alegoria verbal) e allegoria in factis (alegoria factual) (HANSEN, 1987, p. 53). A alegoria verbal dá-se por uma semelhança aparente, incerta, eventual, criada pelo homem, mesmo que esteja alegorizando um fato, esse fato figurado não prefigura outro, o seu acontecimento não tem reflexo em outro acontecimento análogo no decorrer da história, como ocorre na alegoria factual. Se a alegoria verbal é criação do homem, a alegoria factual é criação de Deus, que estabelece uma semelhança escrita, criada e desejada por Ele. Por exemplo, 
São Cipriano declara que Cristo foi prefigurado pelo rei e sacerdote Melquisedeque:

Vemos do mesmo modo, conforme o testemunho da Escritura, o sacramento do Senhor prefigurado no sacerdote Melquisedec. Está dito, com efeito: 'Melquisedec, rei de Salém, trouxe pão e vinho; e ele era sacerdote do Deus Altíssimo. E ele abençoou Abraão' (Gn 14,18). Que Melquisedec tenha sido a figura de Cristo, o Espírito Santo o declara nos Salmos, onde faz dizer ao Filho pelo Pai: 'Tu és sacerdote para sempre, segundo a ordem de Melquisedec'. (SI 110,4 apud SANTO AGOSTINHO, 2002, p. 256).

Deus fala claramente no Novo Testamento o que indicou veladamente no Antigo, cujos fatos têm um análogo na história. No Novo Testamento, Deus parafraseia o Antigo.

Distanciando-se de Beda e de Santo Agostinho, Santo Tomás de Aquino despreza, e mesmo anula, a alegoria verbal. Para ele existem dois sentidos: um literal e outro espiritual. Literal para Tomás de Aquino não é a significação “ao pé da letra", mas a escrita com letras. O homem escreve com letras, Deus escreve com fatos, logo o homem só consegue construir discursos literais. Esses discursos literais, escritos pelo homem, podem ter um sentido literal próprio ou um sentido literal figurado, ou seja, expresso por letras figuradas por metáforas e alegorias. Além do que, para Tomás de Aquino, esses recursos retóricos que constroem as letras figuradas, visam na verdade a realçar o sentido próprio, mesmo porque o leitor, ou ouvinte, reconhece tratar-se de 
metáfora e busca imediatamente o sentido próprio, que é o que interessa. (ECO,1989, p. 99).

Seguindo o raciocínio de Santo Tomás de Aquino, quando Vieira pronuncia que "O Nilo da Igreja Católica é a graça divina”, o ouvinte procura a significação própria do texto. Mas Vieira, como homem, escreve com letras, logo, para Tomás de Aquino, há um sentido literal figurado, não uma alegoria. O que Santo Tomás de Aquino nomeia como sentido espiritual é o que Beda chama de alegoria factual, que para Tomás de Aquino é a única e verdadeira alegoria.

Quaisquer dessas divisões poderiam ser escolhidas para a análise dos Sermões de Padre Antônio Vieira, não importa tanto a nomenclatura que se dê às suas alegorias: quer seja alegoria factual,/alegoria espiritual ou alegoria verbal /sentido literal figurado. O importante é perceber e explicar a função que elas exercem nos discursos.

\section{Alegoria de Renascimento}

Os séculos XV e XVI veem despontar uma nova forma de perceber e apresentar o mundo, sobretudo, pelo renascimento das ideias das sociedades antigas, como a egípcia e a greco-romana. Se o modo de ver o mundo se modifica, modifica-se também o modo de representá-lo. A alegoria desse período é o resultado da analogia levada ao esgotamento lógico, mistura-se alegoria verbal com alegoria factual destituindo a autoria e autoridade de Deus nessa última. A alegoria de renascimento desenvolve-se principalmente em Florença, na Itália, por humanistas como 
Marsilio Ficino, Pico della Mirandola, Christoforo Landino, Lourenço de Medici ${ }^{3}$. Veja-se, em seguida, o exemplo apresentado por Hansen da alegoria de renascimento:

O humanista alemão Conrad Celtes, tendo aprendido sobre as trindades pagãs na Itália, elegeu uma forma singularmente pedante e óbvia, mas pela mesma razão muito instrutiva, de mostrar seu conhecimento numa gravura de madeira, de 1507. Adotou a forma iconográfica tradicional da Santíssima Trindade, mas substitui as figuras cristãs pelas pagãs. No lugar de Deus Pai abençoando o Filho, pôs Júpiter curvando-se sobre seu filho Apolo, enquanto que no Espírito Santo a pomba é substituída pelo alado Pégaso, cujo casco faz surgir a fonte de Hélicon: 'o espírito curvando-se sobre as águas'. A Virgem Maria, ao lado de Cristo, é substituída pela deusa virgem Minerva, e o precursor e profeta João Batista por Hermes, mensageiro dos deuses. No centro das tríades, Apolo tocando lira está provido de seu atributo trinitário, a trípode (que leva expressamente escrito seu nome). As nove musas que emolduram a cena correspondem aos nove coros da hierarquia celeste. (HANSEN, 1997, p. 81).

3 Note-se que, em Portugal, a “[...] forma aristotélica do pensamento por imagens, a difusão dos padrões cortesãos da agudeza e da descrição, a interpretação alegórica e providencialista dos eventos históricos e das coisas da natureza," (HANSEN, 2000, p. 170), impedem que floresça a alegoria de renascimento, que tem por paradigma a Antiguidade oriental e greco-romana com seus emblemas, hieróglifos, mitos etc. 
Observe-se que, na citação, Conrad Celtes constrói uma espécie de tipologia, de alegoria factual, que na Idade Média só podia ser elaborada por Deus. Os deuses da Antiguidade prefiguram, nessa imagem, a Santíssima Trindade, com o uso da analogia de proporção: Júpiter está para Deus, assim como Apolo está para Cristo e Minerva para a Virgem Maria. Isso na Idade Média seria heresia, mas para o humanista é uma forma de construção que aproxima e mescla os mitos pagãos com as verdades cristãs para se chegar à "genealogia ideal, remontando a uma unidade" (HANSEN, 1987, p. 82). Todos os conhecimentos adquiridos pela humanidade até aquele momento são válidos para analisar os mistérios, os enigmas e os hieróglifos dos antigos e também para construir seus próprios enigmas e mistérios.

A arte torna-se jogo de combinações de signos, que forma verdadeiras alegorias perfeitas, para cuja decifração era necessária a operação hermenêutica. Por outras palavras, a alegoria de renascimento utilizava a alegoria verbal, em que as letras e as palavras têm sentido figurado, na elaboração dos seus enigmas; ao mesmo tempo em que seus escritores brincam de ser deuses, criando não só signos dos fatos, mas fatos que são signos.

Utiliza-se Vieira da alegoria de renascimento nas suas prédicas? Basta ler dois ou três capítulos dos sermões de Vieira para perceber que o texto é repleto de citações das passagens e dos fatos bíblicos. Muitas dessas citações têm uma analogia proporcional fortíssima com o assunto do sermão. Vale lembrar que, no Sermão da Terceira Dominga da Quaresma, pregado na Capela Real, no ano de 1655, Vieira denuncia a desonestidade e a malandragem dos 
ministros do rei, que dentre outras coisas, utilizam diversas manobras para se locupletarem.

Ao tratar da questão, Vieira narra, detalhadamente, o modo como Jacó ${ }^{4}$ consegue ser abençoado por seu pai Isaac, no lugar do primogênito Esaú. Parafraseando a passagem: Isaac e Rebeca tiveram filhos gêmeos: Esaú e Jacó. Mas por ter nascido momentos antes, Esaú é o primogênito e, portanto, o destinado a receber a bênção de Isaac. Esaú é, como se sabe, o preferido de Isaac não por ser primogênito, mas pelas suas virtudes, pois era hábil caçador, homem dedicado ao campo; Jacó, ao contrário, é homem de ficar em casa, junto à mãe. Mas Rebeca, preferindo Jacó a Esaú, ludibriou o marido, conseguindo que a bênção fosse dada a Jacó no lugar de Esaú. De que modo procedeu Rebeca? Esaú, a pedido do pai, saíra para caçar, com o objetivo de trazer boa presa com a qual prepararia uma iguaria para o pai, que em seguida lhe daria a bênção. Esta precisa ser dada por Isaac estar velho e cego, pressentindo a morte. Ouvindo o marido falar a Esaú, Rebeca trama uma armadilha, logo que este sai. Ela chama Jacó e lhe pede para ir ao rebanho trazer dois cabritos. Rebeca os prepara ao mesmo tempo em que manda Jacó vestir-se com os trajes de Esaú. Jacó, fingindo ser o irmão, aproxima-se do pai, oferece-lhe a iguaria, recebendo em seguida a bênção de Isaac.

Vieira sugere, a cada momento, a analogia de proporção entre essa narrativa bíblica e a corrupção que envolve os ministros. Como se dá a analogia? Os ministros do rei

4 Jacó ou Jacob, patriarca hebreu, filho de Isaac e de Rebeca. Foi pai de doze filhos, antepassados das doze tribos de Israel. Morreu no Egito, onde seu filho José se tornara ministro do faraó. 
estão para Jacó, assim como seus "padrinhos" políticos estão para Rebeca; o rei (inocente da artimanha) está para Isaac, assim como aqueles que verdadeiramente deveriam ocupar o cargo estão para Esaú. A analogia é tão clara que Vieira diz: "pois isto é o que padecem os Esaús nas preferências dos Jacós".

Note-se que o procedimento de Vieira induz a pensar em termos de alegoria factual, como se o fato ocorrido no Gênesis prefigurasse fato análogo em Portugal e, por consequência, na Colônia. Mas para ser classificada como allegoria in factis, ou tipologia, é preciso que a analogia responda a mais duas exigências: 1) que a semelhança se verifique no Antigo e Novo Testamento, 2) que tenha sido estabelecida por Deus. Contudo, Vieira nessa passagem, não satisfaz a primeira exigência, porque a aproximação não se efetua dentro da própria Escritura, mas entre um fato do Antigo Testamento 5 e Portugal. Logo, o orador lança mão do processo construtivo da alegoria factual, mas não cumpre o pré-requisito, acomodando esse processo ao seu objetivo no discurso: que é denunciar a forma ilícita com a qual os ministros ocupam os cargos. Tais ministros, segundo Vieira, teriam sido prefigurados no Livro Sagrado, é o que se depreende da afirmação subsequente: "pois isto é o que padecem os Esaús nas preferências dos Jacós”, que mostra,

5 O Antigo Testamento tem 46 livros e está estruturado da seguinte maneira: pentateuco (os cinco primeiros livros da Bíblia: Gênesis (= origem do mundo), Exxodo (saída do Egito), Levítico (lei dos sacerdotes da tribo de Levi), Números (contagens ou censos), Deuteronômio (segunda lei); Livros Históricos (dezesseis livros, de Josué a Macabeus); Livros Poéticos e Sapienciais (sete livros: Jó, Salmos, Provérbios, Eclesiastes, Cântico dos Cânticos, Sabedoria, Eclesiástico) e, Livros Proféticos (dezoito livros, de Isaías a Malaquias). 
com o uso do plural, a repetição dessas personagens no tempo, como se fossem (para usar um termo anacrônico) “clones", carregando o mesmo "código genético".

Qual a alegoria que faz acomodações da alegoria factual? A alegoria de renascimento. Logo, Vieira a utiliza nessa passagem? Não, pois não há, nas alegorias de Vieira, dois aspectos da alegoria de renascimento: o ludismo e o paganismo. Que faz então Vieira? Apropria-se dos modos de elaboração da alegoria dos poetas, da alegoria dos teólogos e da alegoria de renascimento, construindo suas alegorias segundo a analogia de atribuição e de proporção. Mas distancia-se da alegoria factual por estender a analogia não mais entre o Antigo e o Novo Testamento, mas entre as Escrituras, a história dos portugueses e a natureza; distancia-se da alegoria de renascimento, visto suas analogias refletirem a "vontade divina", direcionando-a sempre para a utilitas causae, isto é, o tropo despe-se de sua função puramente estética, deixa de ser usado como maquiagem, perfumaria de palavras, e adquire função retórico-argumentativa, tornando-se arma de combate com a qual Vieira procura elucidar questões teológicas e persuadir, politicamente, seus ouvintes; pode-se afirmar que as alegorias possibilitam a Vieira desenvolver uma práxis social e teológica. 


\section{Referências}

ARISTÓTELES. Arte retórica e arte poética. Tradução de Antônio Pinto Carvalho. Rio de Janeiro: Ediouro, 1998. 290 p.

CASTELLO, José Aderaldo. A literatura brasileira. São Paulo: Edusp, 1999. V. 1.

CICERO. El orador. Traductor E. Sáncez Salor. Madrid: Alianza, 1997a. 157 p.

. De la invención retórica. Introducción, traducción y notas: Bulmaro Reyes Coria. México: UNAM, 1997b. 204 p.

ECO, Umberto. Arte e beleza na estética medieval. Tradução de Roberto Romano. 2. ed. Rio de Janeiro: Globo, 1989.

HANSEN, João Adolfo. Alegoria: construção e interpretação da metáfora. 2. ed. São Paulo: Atual, 1987.112 p.

. Vieira: tempo, alegoria e história. Brotéria, Lisboa, v. 146, p. 541-556, 1998.

- Vieira, estilo do céu, xadrez de palavras.

Discurso, São Paulo, n. 9, p. 173-193, 1978.

. Ler \& ver: pressupostos da representação colonial. Furtunecity. Disponível em: <http://www.victorian. 
fortunecity.com/statue/44/zlerverpressupostos.htm $>$. Acesso em: 22 jan. 2002. . Leituras coloniais. In: ABREU, Márcia (Org.).

Leitura, história e história da leitura. Campinas: Mercado de Letras, 2000. p. 169-182.

. Sem f, sem l, em r: cronistas, jesuítas \& índio no século XVI. Caderno Cedes, São Paulo, n. 30, p. 45-55, 1993.

LISBOA, João Francisco. Vida do padre Antônio Vieira. São Paulo: W.M.JACKSON, 1970, 394 p.

LINS, Ivan. Sermões e cartas do padre Antônio Vieira. 3. ed. Rio de Janeiro: Ediouro, [199-]. 243 p.

PÉCORA, Alcir. Teatro do sacramento: a unidade teológico-retórico-política dos sermões de Antônio Vieira. São Paulo: Universidade de São Paulo; Campinas: Editora da Universidade de Campinas, 1994. 286 p.

.Tópicas políticas dos escritos de Antônio Vieira e outros textos. In: Vieira, Antônio. Escritos históricos e políticos, 1995. p. VII-XXVI

QUINTILIANO. Instituições oratórias. São Paulo: Cultura, 1944. $2 \mathrm{v}$.

SANTO AGOSTINHO. A doutrina cristã. São Paulo: Paulus, 2002. $277 \mathrm{p}$. 
SARAIVA Antonio J. O discurso engenhoso. São Paulo: Perspectiva, 1980.

VIEIRA, Antônio. Sermões Padre Antônio Vieira.

Organização e introdução: Alcir Pécora. São Paulo: Hedra, 2000. 661 p. Tomo 1.

. Sermões Padre Antônio Vieira. Organização e introdução Alcir Pécora. São Paulo: Hedra, 2001. 603 p. Tomo 2.

VILAR, Socorro de Fátima P. A invenção de uma escrita. Anchieta, os jesuítas e suas histórias. Porto Alegre: EDIPUCRS, 2006. 



\section{LIVROS EDUEPB E LATUS}

1. Pluralismo Jurídico: Para além da visão monista - Raíssa de Lima e Melo

2. Mulher, corpo e cuidado - Maria de F. de A. Silveira; e Dulce M. Rosa Gualda

3. Avaliação de serviços: um olhar na qualidade da gestão - (Orgs) Maria José Cariri Benígna; e Maria A. Amado Rivera

4. Farmacêutico na Farmácia - Rosimary S. Cunha Lima; Maria do Carmo Eutálio; e Magnólia de L. S. Targino

5. Representações sociais e saúde - Aliana Fenandes; Maria. do R de Carvalho; e Moisés Domingos Sobrinho

6. EPI Info para iniciantes - (Orgs) Sonia Maria de L. Maciel; e Pedro Henrique de A. e S. Leite

7. Ensino de lingua: do impresso ao virtual - (Orgs) Antonio de Pádua Dias da Silva; Maria de L. L. Almeida; Simone Dália de Gusmão Aranha; e Tereza. N. de Farias Campina

8. A história da mídia regional - C. B de Souza; F. G. de Oliveira; e Gorete M. Sampaio de Freitas

9. Livro de resumo de monografias - Maria Dora Ruiz Temoche

10. Planejamento tributário no campo de incidência do ICMS - Alexandre H. S. Ferreira; e Ana Maria da P. Duarte

11. 1930 - A Revolução que mudou a História do Brasil - (Orgs) João M. L. Santos; Cláudo José L. Rodrigues; Inês Caminha L. Rodrigues; e José Octávio de A. Melo

12. Curso de Direito Constitucional - Lorivaldo da Conceição

13. Fragmentos - Juarez Filgueras de Góis

14. Gênero em questão - (Org) Antonio de Pádua Dias da Silva

15. Jogos eletrônicos - Eliane de M. Silva; Filomena M. G. da S. C Moita; e Robson Pequeno de Souza

16. Nascido do Fogo, Filho da Paz - Ket Jeffson Vasconcelos Leitão

17. Política Tributária e Justiça Social - Alexandre Henrique Salema Ferreira

18. Revista Sócio-Poética - Departamento de Letras da UEPB

19. O Sábio e a Floresta - Moacir Werneck de Castro

20. Universidade e o fazer poético em prosa e poesia - (Orgs) Fabíola Nóbrega; Marcelle V. Carvalho; e Tatiana Fernandes Sant'ana

21. Sustentabilidade - um enfoque sistêmico - (Orgs) Waleska S. Lira; Helio de L. Lira; Maria José dos Santos; e Lincon Eloy de Araújo

22. Bioquímica clínica - uma abordagem geral - Sandra Reis Farias

23. Mortalidade Geral - Epidemologia - Anthonyanny A. Silva Lima; Maria J. Cariri Benigna

24. Estudos Filológicos: Literatura - Cultura - Marinalva Freire da Silva

25. Dicionário de termos relativos a gestão de pessoas - Maria Dora Ruiz Temoche

26. Práticas de Políticas Públicas - (Orgs) Marcelo A. Pereira; Maria da G. A. Pereira; Sandra. M. A de S. Celestino; Sueli Ramos de R. M. Cavalcanti; e Wíliam A. de Lacerda

27. Saúde Humana - (Org) Inácia Sátiro Xavier de França

28. O Segredo de Pergamo - Ket Jeffson Vasconcelos Leitão

29. A queda do meteorito - Giusone Ferreira Rodrigues

30. Trajetória empreendedora: estudo de casos numa realidade local e global (Org) Vera Lúcia Barreto Motta 
31. Identidades de gênero e práticas discursivas - (Org) Antonio de Pádua Dias da Silva

32. O lugar da Educação Física - Maria José de Figueirêdo Gomes

33. O papel político dos fóruns de educação de jovens e adultos - Eduardo Jorge Lopes da Silva

34. Pesquisa histórica - resumo de monografias - (Orgs) Luíra Freire Monteiro; e Flávio Carreiro de Santana

35. Anos de luta - Waldir Porfírio

36. Mulher e violência: histórias do corpo negado - Lígia Pereira dos Santos

37. Agricultura orgânica - José Geraldo R. dos Santos; e Emmanuelly Calina X. R. Santos

38. Sobre o diálogo: introdução a uma leitura filosófica de - Julio Cesar Kestering

39. Novos cenários da Administração - (Org) maria Dora Ruiz Temoche

40. O despertar da cultura - (Org) Marinalva Freire da Silva

41. Manual básico de Radiologia Odontológica - Maria de Fátima Cavalcanti Rodrigues

42. Formas de sociabilidade e instauração da alteridade - Inácia S. Xavier de França; Lorita M. Freitag Paghuca

43. Paremiologia nordestina - Fontes Ibiapina

44. Resistência indígena no Piauí colonial 1718 - 1774 - João Renor F. de Carvalho

45. Planejando o (des)envolvimento local - Roberto Alves de Araújo; e Ana Siqueira de Araújo

46. Deuses em poéticas: estudos de Literatura e Teologia - (Orgs) Salma Farraz; Antonio Magalhães; Eli Brandão; Waldecy Tenório; Douglas Conceição

47. Campina Grande em debate - (Org) Roberto Véras de Oliveira

48. História do Direito e da violência: recortes de uma abordagem interdisciplinar - Marcelo Alves Pereira Eufrásio

49. Contos jurídicos: normas de sobredireito da Lei de Introdução ao Código Civil - Ket Jeffson Vasconcelos Leitão

50. A Bacia do Rio Gramame: Biodiversidade, uso e conservação - (Orgs) José Etam de Lucena Barbosa; e Takako Watanabe; e R. José da Paz

51. Ser criança - repensando o lugar da criança na educação infantil - (Orgs) Glória M. de Souza Melo; Soraya. M. de A. Brandão; e Marinalva. da Silva Mota

52. Estudos Sociais da Ciência e Tecnologia - (Org) Renato Dagnino

53. De portas abertas para o lazer - (Orgs) Elaine Melo de B. Costa Lemos; Eduardo Ribeiro Dantas; e Cheng Hzin Nery Chão

54. Gênero e práticas culturais - (Orgs) Charliton J. dos Santos Machado; Idalina M. F. Lima Santiago; e Maria L. da Silva Nunes

55. Da resistência ao poder - o (P)MDB na Paraíba (1965 / 1999) - José Otávio de Arruda Mello

56. Políticas públicas e desenvolvimento regional - (Orgs) Carlos. A. Máximo Pimenta; Cecília Pescatore Alves

57. Histórias vividas e contadas no Bar do Brito - (Orgs) A. C. Barbosa de Souza; Antonio Guedes Rangel Junior; Clara M. Araújo Pinto; e Sonia Maria A. de Oliveira Brito

58. De memória e de identidade - (Orgs) Antonia M. M. da Slva; Francisco Paulo da Silva; Ivanaldo Oliveira dos Santos; e Maria Edileuza da Costa

59. A luz que não se apaga - Rômulo de Araújo Lima

60. Cálculo avançado - (Orgs) Aldo Trajano Louredo; e Alexandro M. de Oliveira; e Osmundo Alves Lima

61. Fisioterapia na gravidez - (Org) Maria do Socorro B. e Silva

62. Educação Universitária - Pedro Bergamo 
63. Amora - Fidélia Cassandra

64. Educação em questão - recortando temas e tecendo ideias - (Pedro Lúcio Barboza)

65. Ciço de Luzia - Efigênio Moura

66. Zila Mamede - trajetórias literárias e educativas - Charliton José dos Santos Machado

67. A voz da infância e outras vozes - Calos Azevedo

68. A Educação da Mulher em Lima Barreto - (Jomar Ricardo da Silva)

69. Porta aberta à poesia popular - Almira Araújo Cruz Soares

70. Mulheres representadas na literatura de autoria feminina - Antonio de Pádua Dias da Silva

71. Residências terapêuticas - (Orgs) Maria de Fátima de A. Silveira e Hudson Pires de O. Santos Júnior

72. A nuvem de hoje - Braulio Taveres

73. Tecnologias digitais na educação - (Orgs) Robson Pequeno de Sousa; Filomena M. C. da S. C. Moita; e Ana Beatriz Gomes Carvalho.

74. A representação da sogra na obra de Leandro Gomes de Barros - José Itamar Sales da Silva

75. Viagem aos $\mathbf{8 0}$ anos da Revolta de Princesa - Janduí Dantas

76. Cidadania glocal, identidade nordestina - José Marques de Melo

77. Uma nova ciência para um novo senso comum - Marcelo Germano Gomes

78. A feira - o trovador encantado - Maria de Lourdes Nunes Ramalho

79. Nordeste como inventiva simbólica - Geralda Medeiros Nóbrega

80. Era uma vez diferente - Aline Pereira

81. Colecionismo, práticas de campo e representações - Maria Margaret Lopes e Alda Heizer.

82. Ensaios de Antropologia da Política - Elizabeth Christina de Andrade Lima

83. A Bela Acordada - Lígia Pereira dos Santos

84. Eu macharei na tua luta - a vida de ELISABETH TEIXEIRA - (Orgs) Lourdes M. Bandeira; Neide Miele; Rosa M. G. Silveira

85. Apropriação Social da Ciência e da Tecnologia - (Orgs) Maria C. P. I. Hayashi; Cidoval M. de Sousa; e Danilo Rotrberg

86. Midiatização da Ciência - cenários, desafios, possibilidades - (Org) Antonio Fausto Neto

87. Psicologia da Saúde - teoria, intervenção e pesquisa - (Org) Railda Fernandes Alves

88. As periércias de um caçador de ETs - Jorge Dellane da Silva Brito

89. Becquerel e a descoberta da radioatividade - Roberto de Andrade Martins

90. Mpb de $\mathrm{A}$ a Z (2 ediçâo) - Ricardo Anísio

91. ECO - Juarez Filgueras de Góis

92. As três verdades de Deus - Janduí Dantas

93. Sabedoria de cabôco - José Alves Sobrinho

94. Agenda Ambiental - gestão socioambiental - (Org) Antônio Augusto Pereira de Sousa; Djane de Fátima Oliveira; Givanildo Gonçalves de Farias; e Mercília Tavares Jordão

95. Etnografia e Educação - conceitos e usos - Carmen Lúcia Guimarães de Mattos; e Paula Almeida de Castro

96. Orgulho de ser caririzeiro - Victor Paulo Sampaio

97. Genealogia do Direito à Saúde - Marcone do Ó Catão

98. Antonio Carlos Nóbrega em acordes e textos armoriais - Luís Adriano Mendes Costa

99. Identidades \& sensibilidade - o cinema como espaço de leituras - (Org) Iranilson Buriti

100. Dom José Maria Pires - Uma voz fiel à mudança social - (Org) Sampaio Geraldo Lopes Ribeiro 

Sobre o livro

Impressão Gráfica Universitária da UEPB

Formato $14 \times 21 \mathrm{~cm}$

Mancha Gráfica $9,5 \times 16,5 \mathrm{~cm}$

Tipologias utilizadas Minion Pro 11,5/12

Papel Apergaminhado $75 \mathrm{~g} / \mathrm{m}^{2}$ (miolo)

e Cartão Supremo $250 \mathrm{~g} / \mathrm{m}^{2}$ (capa) 
O que poderá talvez deixar mais intrigado o leitor que pela primeira vez se depare com o título Travessias pela Literatura Portuguesa: estudos críticos de Saramago a Vieira é a aparente anomalia na disposição dos nomes que aparecem em subtítulo: de Saramago a Vieira. Não faria mais lógica de Vieira a Saramago? No entanto, quando percorremos o conjunto de oito artigos que compõem este volume, compreendemos que eles não estão dispostos por ordem cronológica. 